\title{
STUDI RANCANG BANGUN KONTRUKSI RUMPON LUBUK LARANGAN DI KABUPATEN BUNGO PROVINSI JAMBI
}

\author{
STUDY OF BUILDING CONSTRUCTION OF FADS LUBUK LARANGAN IN BUNGO \\ REGENCY, JAMBI PROVINCE
}

\author{
Muhammad Natsir Kholis ${ }^{1 *}$, Mohd. Yusuf Amrullah ${ }^{1}$, Sulaeman Martasuganda ${ }^{2}$, \\ Filhamdi Saputra ${ }^{1}$ \\ ${ }^{1}$ Universitas Muara Bungo, Jl. Diponegoro No. 27, Jambi 37211, Indonesia \\ ${ }^{2} I P B$ University, Jl. Raya Dramaga, Bogor, Jawa Barat 16680, Indonesia
}

Teregistrasi I tanggal: 18 April 2020; Diterima setelah perbaikan tanggal: 12 Mei 2020; Disetujui terbit tanggal: 23 Mei 2020

\begin{abstract}
ABSTRAK
Perkembangan teknologi kontruksi rumpon dapat dibuat dengan memodifikasi komponen utama atau membuat kontruksi baru sesuai tujuan dan fungsi rumpon. Penelitian ini dilaksanakan pada bulan Desember 2019 di Laboratorium Terpadu Fakultas Perikanan Universitas Muara Bungo. Tujuan dari penelitian ini untuk merancang bangun kontruksi rumpon yang dioperasikan di lubuk larangan Kabupaten Bungo Provinsi Jambi. Metode yang digunakan pada penelitian ini adalah metode eksperimen (skala laboratorium). Hasil penelitian menunjukan bahwa rumpon lubuk larangan memiliki kontruksi berbentuk persegi panjang menyerupai balok, dengan pelampung berdiameter $1 \mathrm{~m}$ dan tinggi $40 \mathrm{~cm}$, tali berbahan PE dengan panjang $1.94 \mathrm{~m}$ berdiameter $1 \mathrm{~cm}$, badan rumpon terbuat dari rangka besi berukuran panjang $1.4 \mathrm{~m}$, lebar $54 \mathrm{~cm}$ dan tinggi $1.94 \mathrm{~m}$. Atraktor rumpon terdiri dari tali rapia dan paralon serta pemberat berbahan semen cor. Ketahanan rumpon terhadap arus sebesar 37.2914 Kgf dan terhadap angin sebesar 49.5215 Kgf.
\end{abstract}

\section{Kata Kunci: Jambi, Kabupaten Bungo, Lubuk Larangan, Kontruksi Rumpon}

\begin{abstract}
The development of FADs construction technology can be made by modifying the main components or making new construction according to the purpose and function of FADs. This research was conducted in December 2019 at the Integrated Laboratory of the Faculty of Fisheries at Muara Bungo University. The purpose of this study was to design the construction of FADs operated at the lubuk larangan in the Bungo Regency of Jambi Province. The method used in this study is the experimental method (laboratory scale). The results showed that the FADs lubuk larangan has a rectangular construction resembling a block, with a float a diameter of $1 \mathrm{~m}$ and a height of $40 \mathrm{~cm}$, a rope made of PE with a length of $1.94 \mathrm{~m} 1 \mathrm{~cm}$ in diameter, the body of the FADs is made of an iron frame measuring 1.4 $m$ long, $54 \mathrm{~cm}$ wide and height $1.94 \mathrm{~m}$. FADs attractor consists of rapia rope and paralon, sinker made from cast cement. The resistance of FADs to currents is $37.2914 \mathrm{Kgf}$ and to wind is $49.5215 \mathrm{Kgf}$.
\end{abstract}

Keywords: Jambi, Bungo Regency, Lubuk Larangan, FADs

\footnotetext{
Korespondensi penulis:

*Email: kholis2336@gmail.com

DOI: http://dx.doi.org/10.15578/plgc.v1i2.8919
} 


\section{PENDAHULUAN}

Rumpon adalah salah satu teknologi yang berfungsi mengumpulkan ikan pada suatu perairan untuk memudahkan penangkapan ikan dengan alat tangkap yang sesuai, karena posisi daerah penangkapan telah diketahui sejak dini (Hikmah et al., 2017). Selain itu rumpon adalah salah satu teknologi yang multifungsi terutama sebagai alat pengumpul ikan (Subani 1986; Demspster, 2004). Samples \& Sproul (1985) menyatakan bahwa tertariknya ikan di sekitar rumpon disebabkan karena beberapa faktor antara lain: 1) rumpon sebagai tempat berteduh (shading place) untuk beberapa jenis ikan tertentu; 2) rumpon sebagai tempat mencari makan (feeding ground), 3) rumpon sebagai substrat untuk menempatkan telur, 4) rumpon sebagai tempat berlindung dari serangan ikan predator dan 5) rumpon sebagai tempat titik acuan navigasi (meeting point) bagi ikan-ikan yang beruaya.

Perbedaan kontruksi dan desain rumpon disetiap wilayah adalah hal yang mutlak, mengingat letak geografis Indonesia yang merupakan negara kepulauan. Hal yang penting dalam membuat rumpon yaitu ketersediaan bahan baku, daya tahan rumpon terhadap berbagai kondisi perairan dan mudah dioperasikan (Yusfiandayani et al., 2014). Secara umum rumpon pada prinsipnya terdiri dari empat komponen utama, yaitu: 1) pelampung (float); 2) tali-temali; 3) atraktor atau pemikat dan 4) pemberat atau sinker.

Sama hal dengan teknologi lainnya, rumpon juga mengalami perkembangan yang pesat. Beberapa jenis teknologi rumpon yang telah dikembangkan seperti rumpon portable, rumpon hidup (BioFAD), rumpon laut dalam (fish apartement), rumpon cumi-cumi, rumpon lampu (auto-lion) dan rumpon ijuk merupakan hasil pengembangan teknologi rumpon modern.
Perkembangan teknologi kontruksi rumpon dapat dibuat dengan memodifikasi komponen utama atau membuat kontruksi baru sesuai tujuan dan fungsi rumpon. Berdasarkan uraian diatas penelitian ini bertujuan untuk merancang bangun kontruksi rumpon yang dioperasikan di lubuk larangan Kabupaten Bungo Propinsi Jambi.

\section{BAHAN DAN METODE}

Waktu dan Tempat

Penelitian ini dilaksanakan pada bulan Desember 2019, bertempat di Laboratorium Terpadu Fakultas Perikanan Universitas Muara Bungo Kabupaten Bungo Provinsi Jambi.

\section{Pengumpulan Data}

Metode yang digunakan pada penelitian ini adalah metode eksperimen (skala laboratorium) dengan merancang dan membuat prototipe rumpon secara bertahap. Sumber data terdiri dari data primer dan didukung data sekunder.

\section{Analisis Data}

Analisis data yang digunakan yaitu analisis deskriptif. Analisis ini digunakan untuk memberikan gambaran dan penjelasan secara sistematis, faktual, dan akurat mengenai kontruksi, teknik dan pembiayaan rancang bangun rumpon lubuk larangan. Rumus yang digunakan untuk menghitung ketahanan rumpon menggunakan pendekatan hidrodinamika dan aerodinamika sesuai Pers. 1 dan Pers. 2 (Syofyan et al., 2016).

- Tahanan arus (R)

$$
\mathrm{R}=\mathrm{Cd} \times 0,5 \times \rho \times \mathrm{d} \times 1 \times \mathrm{v} 2
$$

Keterangan:

$$
\begin{aligned}
\mathrm{R}= & \text { Tahanan arus laut yang menimpa } \\
& \text { tali jangkar } \\
\mathrm{Cd}= & \text { Coefissien of drag tali jangkar dan } \\
& \text { arah arus sungai/laut; memiliki } \\
& \text { panjang } \pm 1.5 \text { kali kedalaman }
\end{aligned}
$$




$$
\begin{aligned}
& \begin{array}{l}
\text { sungai/laut, nilai } \mathrm{Cd}=(0.56 \\
\text { sampai 0.60) }
\end{array} \\
\rho= & \begin{array}{l}
\text { Densitas air laut } 1025 \mathrm{kgm}^{-3} \\
\text { sedangkan pada air tawar } 1000 \\
\mathrm{kgm}^{-3}
\end{array} \\
\mathrm{~d}= & \text { Diameter tali jangkar }(\mathrm{m}) \\
\mathrm{l}= & \text { Panjang tali jangkar }(\mathrm{m}) \\
\mathrm{v}= & \text { Kecepatan arus laut }(\text { laut bebas }= \\
& 0.75 \mathrm{~m} / \mathrm{dtk}, \text { selat }=1.0 \mathrm{~m} / \mathrm{dtk}) \\
& \text { kecepatan arus sungai rata-rata }= \\
& 0.25 \mathrm{~m} / \mathrm{dtk} .
\end{aligned}
$$

- Tahanan hembusan angin (Rw)

$$
\mathrm{Rw}=\mathrm{Cw} \times \mathrm{Av} \times 0.5 \times \rho \times \mathrm{v} 2 \ldots \ldots
$$

Keterangan:

$$
\begin{aligned}
& \mathrm{Rw}=\text { Tahanan angin terhadap rumpon } \\
& \text { (kgf) } \\
& \mathrm{Cw}=\text { Koefisien tahanan angin tehadap } \\
& \text { rumpon (0.66) } \\
& \mathrm{Av}=\text { Luas penampang frontal rumpon } \\
& \rho=\text { Densitas massa udara }(0.125 \mathrm{kgf}) \\
& \mathrm{v}=\text { Kecepatan angin (angin kencang } \\
& 13.9 \text { sampai } 17.1 \mathrm{~m} / \mathrm{dtk} \text { ) }
\end{aligned}
$$

\section{HASIL DAN BAHASAN \\ HASIL}

\section{Lubuk Larangan}

Lubuk larangan merupakan daerah aliran sungai (DAS) Batanghari yang memiliki kedalaman dan airnya tenang, tempat ini menjadi tempat yang kondusif untuk perkembangbiakan ikan. Masyarakat dilarang keras untuk mengambil ikan di wilayah lubuk larangan ini hingga waktu yang telah disepakati bersama. Secara sederhana lubuk larangan merupakan suatu kawasan tertentu di sungai yang dilindungi dalam masa tertentu (Handayani et al., 2018).

Di Provinsi Jambi, tradisi lubuk larangan ini sebagian besar masih diterapkan, utamanya di daerah pedalaman kampung seperti di Kabupaten Bungo, Merangin, Sarolangun dan wilayah lainnya. Bagi desa yang menerapkan lubuk larangan biasanya memiliki kesepakatan bersama (sumpah serapah) untuk menjaga lubuk larangan dari pelanggaran illegal fishing. Bagi masyarakat yang melanggar akan dikenakan sanksi adat dan temakan sumpah sehingga sakit dan meninggal dunia.

\section{Kontruksi Rumpon}

Kontruksi rumpon lubuk larangan berbentuk persegi panjang (balok) dengan ukuran panjang $1.94 \mathrm{~m}$ dan lebar $54 \mathrm{~cm}$. Bahan yang digunakan merupakan bahan yang mudah didapat dan tahan lama, mengingat lubuk larangan merupakan wilayah yang boleh dilakukan penangkapan (panen) pada waktu tertentu sekitar 6 sampai 12 bulan atau lebih. Komponen utama kontruksi lubuk larangan yaitu: pelampung, tali-temali, atraktor, badan dan pemberat. Menurut jenisnya rumpon lubuk larangan termasuk perairan dangkal, dengan penempatan rumpon di dasar perairan. Lebih jelas kontruksi rumpon lubuk larangan dapat dilihat pada (Gambar 1).

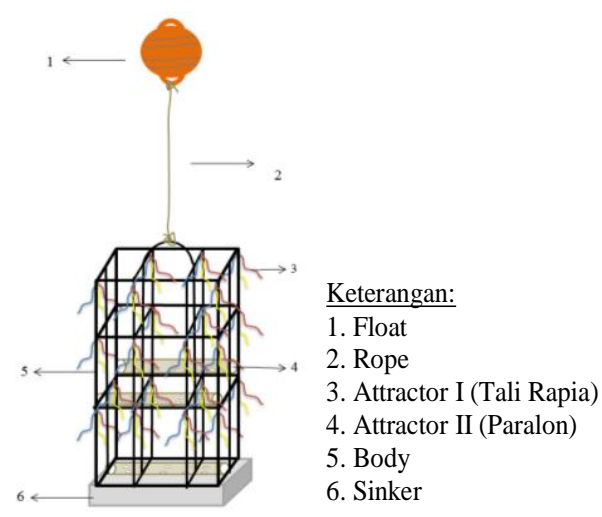

Gambar 1. Kontruksi Rumpon Lubuk Larangan

Figure 1. Contruction of FADs Lubuk Larangan

\section{Pelampung}

Pelampung rumpon lubuk larangan memiliki ukuran berdiameter $1 \mathrm{~m}$ dan tinggi $40 \mathrm{~cm}$ dengan berat $2 \mathrm{~kg}$. Pelampung lubuk larangan berwarna orange, berbahan PP dan berjumlah satu unit. Pelampung berfungsi sebagai tanda dimana rumpon ditempatkan atau ditenggelamkan. 


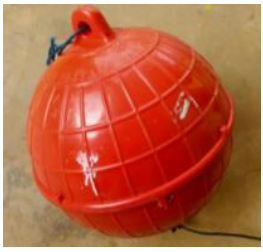

Gambar 2. Pelampung Rumpon Lubuk Larangan Figure 2. Float of FADs Lubuk Larangan

\section{Tali-Temali}

Tali yang digunakan yaitu berbahan PE dengan panjang $1.94 \mathrm{~m}$ berdiameter 1 $\mathrm{cm}$. Tali ini digunakan sebagai pengikat pelampung pada badan rumpon.

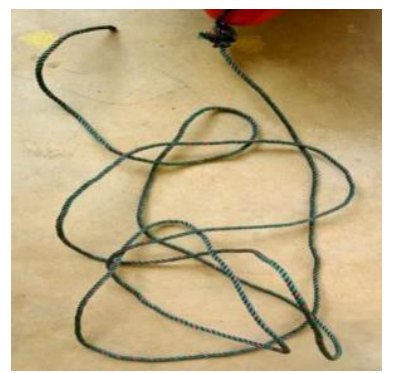

Gambar 3. Tali Temali Rumpon Lubuk Larangan

Figure 3. Rope of FADs Lubuk Larangan

\section{Atraktor/Pemikat}

Atraktor yang digunakan pada rumpon lubuk larangan yaitu tali rapia dan paralon. Kegunaan atraktor ini sebagai pemikat ikan untuk berkumpul disekitar rumpon atau tinggal dan menetap di rumpon.

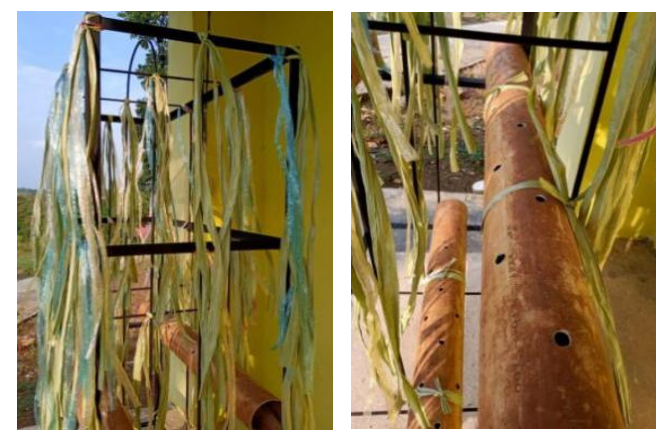

Gambar 4. Atraktor Rumpon Lubuk Larangan Figure 4. Attractor of FADs Lubuk Larangan

\section{Badan}

Badan kontruksi rumpon lubuk larangan ini yaitu rangka besi yang dibuat sejajar dan bersekat, agar memudahkan ikan masuk dan keluar. Badan rumpon lubuk larangan berbentuk persegi panjang berukuran panjang $1.4 \mathrm{~m}$, lebar $54 \mathrm{~cm}$ dan tinggi $1.94 \mathrm{~cm}$.

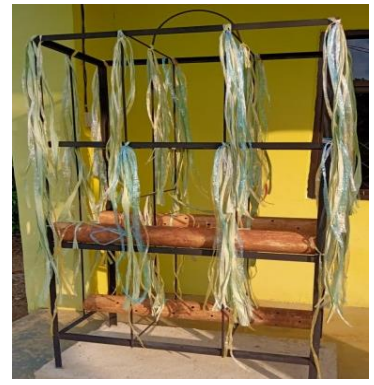

Gambar 5. Badan Rumpon Lubuk Larangan Figure 5. Body of FADs Lubuk Larangan

\section{Pemberat}

Pemberat rumpon lubuk larangan ini berbahan semen cor, memiliki ukuran panjang $1.18 \mathrm{~cm}$, lebar $56 \mathrm{~cm}$ dan tinggi $20 \mathrm{~cm}$ serta memiliki berat sekitar $50 \mathrm{~kg}$. Kegunaan pemberat yaitu untuk menenggelamkan rumpon sampai ke dasar perairan.

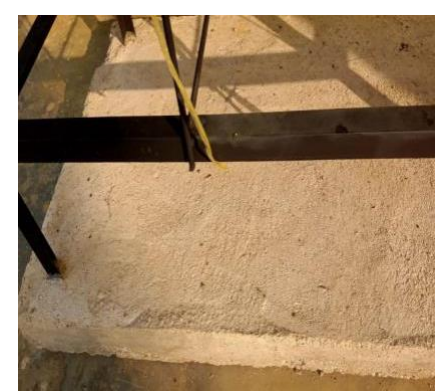

Gambar 6. Pemberat Rumpon Lubuk Larangan Figure 6. Sinker of FADs Lubuk Larangan

\section{Perhitungan Ketahanan Rumpon}

Rumpon yang baik haruslah memiliki ketahanan terhadap lingkungan, baik secara hidrodinamika dan aerodinamika. Pada penelitian ini, rumpon lubuk larangan diuji ketahanan terhadap arus dan angin. Sebelum diuji ketahanan tersebut, maka dilakukanlah 
pengukuran dimensi dan spesifikasi terhadap rumpon yang telah dibuat. Hasil pengukuran dimensi kontruksi rumpon lubuk larangan dapat dilihat pada (Tabel $1)$.

Hasil perhitungan ketahanan rumpon lubuk larangan terhadap arus dan angin didapatkan ketahanan terhadap arus sebesar 37.2914 Kgf dan terhadap angin sebesar 49.5215 Kgf. Pelampung memiliki ketahanan tertinggi diantara lainnya sebesar $36.267 \mathrm{Kgf}$ terhadap arus dan 37.8744 Kgf terhadap angin. Sedangkan badan rumpon memiliki ketahanan terendah sebesar $0.02567 \mathrm{Kgf}$ terhadap arus dan $0.0177 \mathrm{Kgf}$ terhadap angin. Ketahanan rumpon lubuk larangan terhadap arus dan angin lebih jelas dapat dilihat pada (Tabel 2).

Tabel 1. Dimensi dan Spesifikasi Rumpon Lubuk Larangan

Table 1. Dimensions and Specifications of FADs Lubuk Larangan

\begin{tabular}{|c|c|c|c|c|}
\hline No & Komponen & Material & Ukuran & Jumlah \\
\hline 1 & Pelampung & PP (Warna: orange) & Tinggi: $40 \mathrm{~cm}, \varnothing: 1 \mathrm{~m}$ & 1 \\
\hline 2 & Tali & PE (Warna: hijau tua) & Panjang: $1.94 \mathrm{~m}, \varnothing: 1 \mathrm{~cm}$ & 1 \\
\hline 3 & Atraktor I & $\begin{array}{l}\text { Tali rapia (Warna: biru, } \\
\text { kuning, merah) }\end{array}$ & Panjang: $90 \mathrm{~cm}$ & 150 \\
\hline 4 & Atraktor II & Paralon & Panjang: $1.3 \mathrm{~m}, \varnothing: 1.5 \mathrm{~cm}$ & 3 \\
\hline 5 & $\begin{array}{l}\text { Badan } \\
\text { Rumpon }\end{array}$ & Rangka Besi & $\begin{array}{l}\text { Panjang: } 1.4 \mathrm{~cm} \text {, Lebar: } 54 \\
\mathrm{~cm} \text {, Tinggi: } 1.94 \mathrm{~m}\end{array}$ & $\begin{array}{l}\text { Vertikal: } 10 \text {, } \\
\text { Horizontal: } 6\end{array}$ \\
\hline 6 & Pemberat & Semen Cor & $\begin{array}{l}\text { Panjang: } 1.18 \mathrm{~cm} \text {, Lebar } \\
56 \mathrm{~cm} \text {, Tinggi: } 20 \mathrm{~cm}\end{array}$ & 1 \\
\hline
\end{tabular}

Tabel 2. Perhitungan Ketahanan Rumpon Lubuk Larangan Terhadap Arus dan Angin

Table 2. Calculation of Resistance of FADs Lubuk Larangan Prohibition Against Currents and Wind

\begin{tabular}{crcc}
\hline \multirow{2}{*}{ No } & \multirow{2}{*}{ Komponen } & \multicolumn{2}{c}{ Ketahanan } \\
\cline { 3 - 4 } & & Arus $(\mathrm{R})(\mathrm{Kgf})$ & Angin $(\mathrm{Rw})(\mathrm{Kgf})$ \\
\hline 1 & Pelampung & 36.267 & 37.8744 \\
2 & Tali & 0.50925 & 0.03510 \\
3 & Atraktor I & 0.45833 & 10.8557 \\
4 & Atraktor II & 0.03118 & 0.7386 \\
5 & Badan Rumpon & 0.02567 & 0.0177 \\
\hline \multicolumn{2}{c}{ Rtot } & 37.2914 & 49.5215 \\
\hline
\end{tabular}

\section{Pengoperasian Rumpon}

Metode pengoperasian alat bantu penangkapan ikan rumpon dilakukan dengan membawa rumpon yang telah dibuat menuju lokasi pemasangan/penempatan rumpon, yaitu lubuk larangan. Jumlah nelayan/orang yang dibutuhkan dalam pengoperasinnya berkisar 5 sampai 10 orang. Penurunan rumpon dilakukan dengan menjatuhkan bagian bawah rumpon (pemberat) dan menahan tali pelampung secara perlahan dari atas permukaan perairan, kemudian dua orang menyelam untuk memastikan rumpon jatuh pada posisi yang benar di dasar perairan. Setelah rumpon sampai di dasar perairan, maka pelampung akan mengapung diatas perairan.

Kedalaman lubuk larangan berkisar 2 sampai 6 meter dengan lebar \pm 25 meter dan panjang bisa mencapai $1 \mathrm{~km}$ tergantung lokasi lubuk larangannya. Rumpon lubuk larangan ini bersifat menetap, sehingga ikan yang berada di 
rumpon lubuk larangan dapat dan perairan tenang, kualitas perairan berkembang biak secara alamiah.

Waktu yang diperlukan untuk menurunkan/memasang rumpon lubuk larangan ini berkisar antara 30 sampai 60 menit. Lokasi lubuk larangan atau penempatan rumpon yang dapat di pasang rumpon ini dilihat dari berbagai aspek seperti: lokasi/tempat pemasangan aman masih kategori baik, merupakan ruaya atau habitat ikan, tidak menganggu aktivitas masyarakat atau lainnya serta mendapat izin dari pemerintah atau kelompok masyarakat. Lebih jelas pengoperasian dan penempatan rumpon lubuk larangan di dasar perairan dapat dilihat pada (Gambar 7).

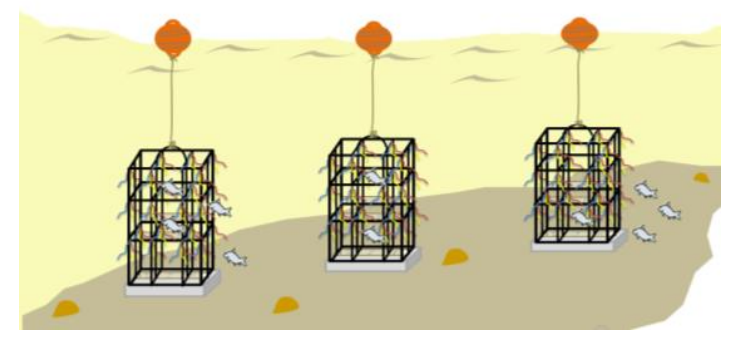

Gambar 7. Metode Pengoperasian Rumpon Lubuk Larangan

Figure 7. Method of Operating the FADs Lubuk Larangan

\section{Biaya Pembuatan Rumpon}

Pembuatan rumpon lubuk larangan dibuat sedemikian rupa dengan memerhatikan jangka waktu pengoperasian, untuk itu digunakan bahan-bahan dengan kualitas terbaik. Hal itu menyebabkan biaya awal untuk pembuatan rumpon lubuk larangan terbilang tinggi bagi masyarakat Desa, tetapi tidak menutup kemungkinan bahan material dapat diganti sesuai kebutuhan masyarakat Desa. Biaya bahan habis pakai pembuatan rumpon lubuk larangan yaitu sebesar Rp.770.000,- dan biaya pengadaan alat sebesar Rp.465.000,sehingga total biaya pembuatan sebesar Rp.1.235.000,-. Lebih jelas biaya pembuatan rumpon lubuk larangan dapat dilhat pada (Tabel 3).

Tabel 3. Biaya Pembuatan 1 Unit Rumpon Lubuk Larangan

Table 3. Cost of Making 1 Unit FADs Lubuk Larangan

\begin{tabular}{|c|c|c|c|c|c|}
\hline No & Komponen & Satuan & volume & Satuan & Harga (Rp) \\
\hline \multicolumn{6}{|c|}{ Bahan habis pakai } \\
\hline 1 & Semen & 2500 & 20 & $\mathrm{Kg}$ & 50000 \\
\hline 2 & Tali Rapia & 12000 & 4 & Unit & 48000 \\
\hline 3 & Paralon & 47000 & 3 & Batang & 141000 \\
\hline 4 & Besi & 55000 & 8 & Batang & 440000 \\
\hline 5 & Pelampung & 40000 & 1 & Unit & 40000 \\
\hline 6 & Pasir & 3000 & 10 & $\mathrm{Kg}$ & 30000 \\
\hline 7 & Cat Besi & 15000 & 1 & Kaleng & 15000 \\
\hline 8 & Kuas & 6000 & 1 & Unit & 6000 \\
\hline \multicolumn{6}{|l|}{ Alat } \\
\hline 1 & Gunting & 10000 & 2 & Unit & 20000 \\
\hline 2 & Alat Las & 350000 & 1 & Paket & 350000 \\
\hline 3 & Cangkul & 55000 & 1 & Unit & 55000 \\
\hline 4 & Ember & 20000 & 2 & Unit & 40000 \\
\hline \multicolumn{5}{|c|}{ Jumlah Biaya } & 1235000 \\
\hline
\end{tabular}




\section{BAHASAN}

Rumpon ini dinamakan rumpon lubuk larangan karena lokasi/penempatan operasi rumpon ini di lubuk larangan. Lubuk larangan terus berkembang dari satu dusun ke dusun lainnya. Pada akhir tahun 2018 tercatat jumlah lubuk larangan di Kabupaten Bungo berjumlah 128 lubuk (Dinaskkan Kabupaten Bungo, 2018). Keberadaan lubuk larangan merupakan salah satu wujud upaya konservasi sumberdaya perikanan yang memiliki peranan penting bagi masyarakat. Tata cara pembentukan kawasan konservasi itu telah diatur dalam Peraturan Pemerintah Nomor 60 Tahun 2007 Tentang Konservasi Sumber Daya Ikan dan Peraturan Menteri Kelautan dan Perikanan RI Nomor PER.02/MEN/2009 Tentang Tata Cara Penetapan Kawasan Konservasi Perairan.

Keberadaan suaka perikanan secara hukum dijamin berdasarkan pada Undang-undang Nomor 45 Tahun 2009 Tentang Perikanan, Peraturan Pemerintah Nomor 60 Tahun 2007 Tentang Konservasi Sumberdaya Ikan. Sedangkan tata cara penetapan kawasan konservasi perairan diatur dengan Peraturan Menteri Kelautan dan Perikanan No: PER.02/MEN/2009. Berdasarkan tujuan pengelolaan, suaka perikanan memiliki kriteria:

a. Tempat hidup dan berkembang biak satu atau lebih jenis ikan tertentu yang perlu dilindungi dan dilestarikan;

b. Memiliki satu atau beberapa tipe ekosistem sebagai habitat jenis ikan tertentu yang relatif masih alami; dan/atau

c. Memiliki luas perairan yang mendukung keberlangsungan proses ekologis secara alami sebagai habitat ikan serta dapat dikelola secara efektif.

Rumpon lubuk larangan ini diharapkan menjadi solusi dari perkembangan lubuk larangan. Selain untuk menjaga perkembangbiakkan ikan, rumpon lubuk larangan ini berguna juga untuk meningkatkan hasil tangkapan saat pembukaan lubuk larangan (panen), karena ikan sudah banyak berkumpul di sekitar rumpon.

Secara umum kontruksi rumpon lubuk larangan yang dibuat merupakan hasil pengamatan di lapangan, dengan memperhatikan kondisi perairan dan jenis spesies yang ada di lubuk larangan. Jenis ikan yang banyak terdapat di lubuk larangan merupakan ikan yan memiliki tingkah laku (behaviour) bersembunyi dan berteduh. Menurut Widya (2017), di sungai Batang Bungo didapatkan 11 Spesies, 5 Famili, dan 3 Ordo. Adapun spesiesnya yaitu ikan Osphronemus gouramy (Kalui), Mytus micracanthus (Baung), Hampala macrolepidota (Barau), Barbodes schwanenfeldii (Lampam), Mystacoleucus marginatus (Kusut Masai), Anabas testudienus (Betok), Barbichtys laevis (Mentulu), Pristolepisgrootii (Kerak Baluh), Mytus nigriceps (Ingir-ingir), Osteochilus hasseltii (Palau) dan Cyclocheilichthys apogon (Pelepang).

Sedangkan menurut Patri et al. (2019), reservat (lubuk larangan) lubuk manik ditemukan 17 Spesies, 17 Genus dari 8 Famili dan 4 Ordo. Spesies yang ditemukan terdiri dari: Puntius schwanefeldi (Kefiat), Neolissochilus sumatranus (Simancung), Osteochilus hasseti (Palau), Osteochilus hasselti (Nilem), Barbonymus gonionotus (Tawes), Labiobarbus fasciatus (Masik), Dangila cuvieri (Umbu-Umbu), Hampala sp. (Barau), Rasbora argyrotaenia (Seluang), Cryptopterus limpok (Lais), Osphronemus gouramy (Gurami), Leiocassic sp. (Kepuntin), Mystus nemurus (Baung), Trichogaster trichopterus (Sepat), Helostoma temminckii (Tambakan), Mastacembelus maculatus (Tilan), dan Oxyeleotris marmorata (Betutu).

Memperhatikan kondisi perairan dan beberapa jenis ikan tersebut maka kontruksi rumpon lubuk larangan dibuat dengan konsep modern tetapi alami 
sebagai rumah bagi ikan. Perkembangan teknologi kontruksi rumpon yang telah dibuat mengalami terus perubahan sesuai tujuan penangkapan, pada penelitian ini rumpon lubuk larangan dibuat berbentuk persegi panjang (balok) sesuai kemampuan renang ikan (swimming layer).

Menurut Yusfiandayani et al. (2014), prototipe rumpon portable berbentuk persegi, dengan ukuran panjang dan lebar sebesar 1 meter, bahan yang digunakan kayu manglid, atraktor yang digunakan tali rafia, tali atraktor dan tali pemberat adalah tali PE berdiameter 4 mm. Sedangkan menurut Suardi (2017), konstruksi rumpon hidup (BioFAD) hasil rancangan berbentuk silinder atau tabung. Rumpon hidup hasil rancangan dapat memikat ikan yang berukuran juvenil maupun ikan yang berukuran dewasa. Rumpon hidup tersebut dirancang hanya satu bentuk namun yang membedakan adalah jenis rumput laut yang digunakan sebagai atraktor yaitu: 1) rumput laut jenis Eucheuma cottonii dan 2) rumput laut jenis Gracillaria sp. Penggunaan dua jenis rumput laut tersebut sebagai atraktor menjadi nama dari rumpon hidup yang dibuat yaitu rumpon cottonii (RC) dan rumpon gracillaria (RG). Selain itu menurut Syari et al. (2014), jenis modifikasi rumpon cumi-cumi terdiri atas 2 jenis yaitu 1) rumpon cumi bentuk kotak dengan ukuran $75 \times 50 \times 35 \mathrm{~cm}^{3}$ dengan kerangka dari kayu dan 2) rumpon cumi-cumi berbentuk silindris dari drum bekas. Ditambahkan Chairunnisa et al. (2018); Taufiq et al. (2015), kontruksi rumpon Auto-Lion (Automatic Lighting Rumpon) berbentuk prisma segi empat dengan ukuran ( $\mathrm{p} \times 1 \mathrm{x}$ t) $24 \times 11 \times 11 \mathrm{~cm}^{3}$ dan memiliki 6 buah lampu LED berkekuatan 10 watt yang dipasang pada sisi ujung rumpon.

Dimensi dan spesifikasi rumpon baik dari bentuk dan komponen/bagian utama rumpon juga memiliki perbedaan. Rumpon lubuk larangan memiliki pelampung berbahan PP berdiameter $1 \mathrm{~m}$ dan tinggi $40 \mathrm{~cm}$ dengan berat $2 \mathrm{~kg}$. Menurut Suardi et al. (2016), rumpon hidup menggunakan pelampung (float) berbahan gabus $(1=60 \mathrm{~cm}$ dan $\mathrm{t}=45 \mathrm{~cm})$. Sedangkan menurut Hikmah et al. (2017), rumpon di Jeneponto memiliki pelampung berbahan Styrofoam tinggi $100 \mathrm{~cm}$ dan lebar $60 \mathrm{~cm}$. Jenis pelampung pontoon banyak digunakan oleh nelayan di Indonesia Timur seperti di Kendari, Bitung dan Sorong, sedang jenis rakit dan gabus (foam) banyak digunakan oleh nelayan di wilayah bagian barat seperti di Jawa dan Sumatera (Wudianto et al., 2019).

Tali rumpon lubuk larangan berbahan PE dengan panjang $1.94 \mathrm{~m}$ dan berdiameter $1 \mathrm{~cm}$. Hal ini sesuai pendapat Hikmah et al. (2017) bahwa tali yang digunakan rumpon di Jeneponto yaitu berbahan PE dengan panjang 15-17 m untuk kedalaman $8-10 \quad \mathrm{~m}$, tali $\mathrm{PE}$ panjang $25 \mathrm{~m}$ untuk kedalaman $15 \mathrm{~m}$, dan tali PE panjang $35 \mathrm{~m}$ untuk kedalaman 25 m. Ditambahakan Suardi et al., (2016), tali rumpon hidup menggunakan tali jenis nilon atau polyethylene (PE) no. 4, 6 dan 8. Pemilihan tali PE dikarenakan PE dapat bertahan di dalam air dalam waktu yang lama sehingga lebih ekonomis bagi nelayan (Hikmah et al., 2017). Tali temali biasanya digunakan dari bahan sintetis seperti polyethelene atau bahan alami dari rosella. Panjang tali yang digunakan dapat mencapai 1.5 sampai 2 kali dari kedalaman perairan dimana rumpon dipasang (Wudianto et al., 2019).

Atraktor yang digunakan pada rumpon lubuk larangan yaitu tali rapia dan paralon. Menurut Hikmah et al., (2017), atraktor merupakan bagian yang penting sebagai alat pengumpul ikan, rumpon di Jeneponto menggunakan atraktor berbahan daun kelapa dengan panjang $3.7 \mathrm{~m}$ berjumlah 8 sampai 25 helai. Pemilihan jenis aktraktor daun kelapa memberi peluang tumbuhnya mikroorganisme penempel pada permukaan daun kelapa sebagai sumber nutrien bagi ikan pelagis kecil. 
Sedangkan menurut Thahir et al. (2019), tali rapia dapat dijadikan sebagai atraktor karena mampu memikat ikan berkumpul dan dapat dijadikan tempat menempelnya mikroorganisme kecil bahkan telur ikan. Menurut Syari et al. (2014) dan Baskoro et al. (2017), bentuk dan bahan utama atraktor cumi-cumi adalah tali rami (bahan organik) diletakkan berdiri vertikal pada bagian tengahnya dan bagian rangkanya pada sisi bagian atas ditutupi waring yang bertujuan untuk membuat kondisi dalam atraktor teduh atau agak gelap. Hal itu bertujuan agar cumi-cumi tertarik meletakkan telurnya di dalam rumpon cumi-cumi yang telah ditenggelamkan. Jenis atraktor lain seperti yang digunakan rumpon hidup yaitu menggunakan bahan rumput laut $(E$. cottonii dan Gracillaria sp. dengan berat masing-masing $25 \mathrm{~kg}$ (Suardi et al., 2016).

Badan kontruksi rumpon lubuk larangan ini yaitu rangka besi yang dibuat sejajar dan bersekat, berukuran panjang $1.4 \mathrm{~m}$, lebar $54 \mathrm{~cm}$ dan tinggi $1.94 \mathrm{~cm}$. Menurut Suardi et al. (2016), badan (body) rumpon hidup menggunakan bahan dari bambu $(\mathrm{t}=180 \mathrm{~cm}, 1=2 \mathrm{~cm})$ sebagai rusuk dan rotan $(\mathrm{p}=160 \mathrm{~cm}, \varnothing=$ $1.5 \mathrm{~cm}$ ) sebagai lingkaran rumpon.

Pemberat rumpon lubuk larangan berbahan semen cor, memiliki ukuran panjang $1.18 \mathrm{~cm}$, lebar $56 \mathrm{~cm}$ dan tinggi $20 \mathrm{~cm}$ serta memiliki berat sekitar $50 \mathrm{~kg}$. Menurut Hikmah et al. (2017), pemberat yang biasa digunakan yaitu batu, blok semen, semen cor/beton, ataupun jangkar kapal bisa juga digunakan sebagai pemberat. Sedangkan menurut Suardi et al. (2016), pemberat (sinker) yang digunakan rumpon hidup yaitu bahan campuran (berat $45 \mathrm{~kg}$ ) dan tali nilon PE no. 10 untuk tali pemberat atau jangkar. Pemberat rumpon berfungsi untuk mempertahankan agar tidak hanyut dan tetap berada pada posisi yang dikehendaki (Hikmah et al., 2017).

Rumpon yang dirancang harus diuji ketahanan terhadap arus dan angin, agar memiliki performa yang baik saat ditenggelamkan. Rumpon lubuk larangan merupakan rumpon dasar perairan sehingga gaya tenggelam lebih dominan. Ketahanan rumpon lubuk larangan terhadap arus dan angin didapatkan ketahanan terhadap arus sebesar 37.2914 Kgf dan terhadap angin sebesar 49.5215 Kgf. Menurut Suardi et al. (2016), rumpon hidup (BioFAD) memiliki gaya statis pada perairan tawar sebesar 274 . 378.00 gram, sedangkan jumlah total gaya tenggelam sebesar -175.518 .00$ gram dan gaya apung tambahan (extra buoyancy) sebesar 81\%. Gaya statis rumpon hidup di perairan laut yaitu gaya apung sebesar 281.237.45 gram, sedangkan jumlah total gaya tenggelam sebesar -6.858.45 gram dan gaya apung tambahan sebesar $98 \%$. Total gaya apung, gaya tenggelam dan gaya apung tambahan di perairan laut lebih besar dari pada di perairan tawar.

Pembuatan rumpon lubuk larangan menghabiskan biaya sebesar Rp.1.235.000,- terdiri dari bahan habis pakai dan perlengkapan alat. Pembiayaan digunakan hanya untuk merancang bangun 1 unit rumpon sampai selesai. Menurut Suardi (2017), analisis finansial untuk rumpon hidup dimaksudkan untuk mengetahui kelayakan usaha per unit rumpon hidup per tahun. Biaya tetap rumpon hidup per unit sebesar Rp. 374.000,- biaya variabel sebesar $\mathrm{Rp}$. $1.050 .000,-$ dan total biaya yang digunakan sebesar 1.424.000,-, sedangkan rata-rata penerimaan rumpon hidup per unit per tahun sebesar Rp. 2.200.000,- sehingga pendapatan rumpon hidup per unit per tahun sebesar Rp. 776.000,-. Selanjutnya untuk menentukan kelayakan usaha rumpon hidup dapat dilakukan dengan menggunakan pendekatan R/C atau Revenue/Cost. Hasil analisis menunjukan bahwa $\mathrm{R} / \mathrm{C}=1.45$. Hasil ini mengindikasikan bahwa usaha rumpon hidup di perairan pesisir Uloulo Kabupaten Luwu layak diusahakan. 


\section{SIMPULAN}

Hasil dari penelitian ini dapat disimpulkan bahwa rumpon lubuk larangan memiliki kontruksi berbentuk persegi panjang menyerupai balok, dengan pelampung berdiameter $1 \mathrm{~m}$ dan tinggi $40 \mathrm{~cm}$, tali berbahan PE dengan panjang $1.94 \mathrm{~m}$ berdiameter $1 \mathrm{~cm}$, badan rumpon terbuat dari rangka besi berukuran panjang $1.4 \mathrm{~m}$, lebar $54 \mathrm{~cm}$ dan tinggi $1.94 \mathrm{~m}$. Atraktor rumpon terdiri dari tali rapia dan paralon serta pemberat berbahan semen cor. Ketahanan rumpon terhadap arus sebesar $37.2914 \mathrm{Kgf}$ dan terhadap angin sebesar $49.5215 \mathrm{Kgf}$.

\section{UCAPAN TERIMA KASIH}

Penulis mengucapkan terima kasih kepada semua pihak yang telah membantu penulis sehingga penelitian ini dapat dilaksanakan. Terkhusus kepada kepala Laboratorium Terpadu Fakultas Perikanan Ibu Ir. Sri Maryeni, M.Si dan Dekan Fakultas Perikanan Universitas Muara Bungo Ibu Rini Hertati, S.Pi, M.Si atas support dan pembiayaan pada penelitian ini.

\section{DAFTAR PUSTAKA}

Baskoro, M. S., Sondita, M. F. A., Yusfiandayani, R., \& Syari, I. A. (2017). Efektivitas Bentuk Atraktor Cumi-Cumi Sebagai Media Penempelan Telur CumiCumi (Loligo sp). Jurnal Kelautan Nasional, 10(3), 177-184.

Chairunnisa, S., Setiawan, N., Ekawati, K., Anwar, A., \& Fitri, A. D. (2018). Studi Tingkah Laku Ikan Terhadap Prototype Auto-Lion (Skala Laboratorium). Marine Fisheries: Journal of Marine Fisheries Technology and Management, 9(1), 55-63.

Dempster, T. (2004). Biology of Fish Associated with Moored Fish Aggregation Devices (FADs):
Implications for the Development of a FAD Fishery in New South Wales, Australia. Fisheries Research, 68(1-3), 189-201.

[Disnakkan] Dinas Peternakan dan Perikanan. (2018). Laporan Tahunan Statistik Perikanan Tangkap Dinas Peternakan dan Perikanan Kabupaten Bungo, Muara Bungo Provinsi Jambi. Jambi: Disnakkan.

Handayani, M., Djunaidi, \& Hertati, R. (2018). Sistem Pengelolaan Lubuk Larangan Sebagai Bentuk Kearifan Lokal di Sungai Batang Tebo Kabupaten Bungo Provinsi Jambi. SEMAH: Jurnal Pengelolaan Sumberdaya Perairan, 2(3).

Hikmah, N., Kurnia, M., \& Amir, F. (2017). Pemanfaatan Teknologi Alat Bantu Rumpon untuk Penangkapan Ikan di Perairan Kabupaten Jeneponto. Jurnal IPTEKS Pemanfaatan Sumberdaya Perikanan, 3(6), 455-468.

Peraturan Pemerintah Republik Indonesia Nomor 60 Tahun 2007 Konservasi Sumber Daya Ikan. 16 Nopember 2007. Lembaran Negara Republik Indoneis Tahun 2004 Nomor 118. Jakarta.

Patri, S., Hertati, R., \& Djunaidi, D. (2019). Studi Kualitas Air dan Keanekaragaman Jenis Ikan di Suaka Perikanan (Reservat) Lubuk Manik Kecamatan Rantau Pandan Kabupaten Bungo Provinsi Jambi. SEMAH Jurnal Pengelolaan Sumberdaya Perairan, 3(1).

Peraturan Menteri Kelautan dan Perikanan Nomor 02 Tahun 2009 Tata Cara Penetapan Kawasan Konservasi Perairan. 12 Februari 2009. Berita Negara Republik Indonesia. Jakarta.

Samples, K. C., \& Sproul, J. T. (1985). Fish Aggregating Devices and Open-Access Commercial Fisheries: A Theoretical Inquiry. 
Bulletin of Marine Science, 37(1), 305-317.

Suardi. (2017). Rancang Bangun Rumpon Hidup (BioFAD) dan Uji Efektivitas Serta Keramahan Lingkungan di Perairan Pesisir Uloulo Kabupaten Luwu. Disertasi. Program Pasca Sarjana Institut Pertanian Bogor. Bogor.

Suardi, S., Wiryawan, B., Santoso, J., \& Riyanto, M. (2016). Rumpon Hidup dan Hubungannya dengan Struktur Komunitas Ikan Secara Spasialtemporal di Pesisir Kabupaten. Marine Fisheries, 7(1), 83-95.

Subani, W. (1986). Telaah Penggunaan Rumpon dan Payaos dalam Perikanan Indonesia. Jurnal Penelitian Perikanan Laut, 35, 3545.

Syari, I. A., Kawaroe, M., \& Baskoro, M. S. (2014). Perbandingan Efektivitas Rumpon Cumi-Cumi Menurut Musim, Kedalaman dan Jenis Rumpon. Jurnal Penelitian Perikanan Indonesia, 20(1), 63-72. Syofyan, I., Syaifuddin, S., \& Thahir, M. A. (2016). Alat Bantu Penangkapan Ikan. Buku Ajar Jurusan Pemanfaatan Sumberdaya Perikanan Fakultas Perikanan dan Ilmu Kelautan Universitas Riau. Riau: UNRI Press.

Taufiq, T., Mawardi, W., Baskoro, M. S., \& Zulkarnain, Z. (2015). Rekayasa Lampu LED Celup Untuk Perikanan Bagan Apung di Perairan Patek Kabupaten Aceh Jaya
Propinsi Aceh. Jurnal Teknologi Perikanan dan Kelautan, 6(1), 5167.

Thahir, M. A., Baskoro, M. S., \& Gazali, M. (2019). Perbandingan Hasil Tangkapan Pada Rumpon Tali Rafia Dan Rumpon Tradisional di Perairan Aceh Barat. Jurnal Ilmu dan Teknologi Kelautan Tropis, 11(2), 369-376.

Undang-Undang Republik Indonesia Nomor 45 Tahun 2009 Perubahan Atas Undang-Undang Nomor 31 Tahun 2004 tentang Perikanan. Lembaran Negara Republik Indonesia Tahun 2009 Nomor 154. Jakarta.

Widya, A. (2017). Spesies Ikan Di Batang Bungo Desa Rantau Pandan Kecamatan Rantau Pandan Kabupaten Bungo Provinsi Jambi. Disertasi. Program Pasca Sarjana STKIP PGRI Sumatera Barat. Padang.

Wudianto, W., Widodo, A. A., Satria, F., \& Mahiswara, M. (2019). Kajian Pengelolaan Rumpon Laut Dalam sebagai Alat Bantu Penangkapan Tuna di Perairan Indonesia. Jurnal Kebijakan Perikanan Indonesia, 11(1), 23-37.

Yusfiandayani, R., Jaya, I., \& Baskoro, M. S. (2014). Konstruksi dan Produktivitas Rumpon Portabel di Perairan Palabuhanratu, Jawa Barat. Jurnal Teknologi Perikanan dan Kelautan, 5(2), 117-127. 